\title{
Research Paper: Effects of Metformin on Weight Loss and Metabolic Control in Obese Patients With Schizophrenia and Schizoaffective Disorder: A Randomized Double-Blind Controlled Clinical Trial
}

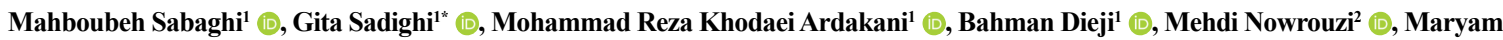 \\ Aghaye Rashti ${ }^{3}$ iD, Sasan Zandi Esfahan ${ }^{4}$ iD
}

1. Department of Psychiatry, University of Social Welfare and Rehabilitation Sciences, Tehran, Iran

2. Department of Statistics, University of Social Welfare and Rehabilitation Sciences, Tehran, Iran.

3. Department of Statistics, Shahid Beheshti University, Tehran, Iran.

4. Department of Nursing and Midwifery, Najafabad Branch, Islamic Azad University, Isfahan, Iran.

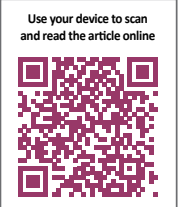

ditation: Sabaghi M, Sadighi G, Khodaei Ardakani MR, Dieji B, Nowrouzi M, Aghaye Rashti M, Zandi Esfahan S. Effects of Metformin on Weight Loss and Metabolic Control in Obese Patients With Schizophrenia and Schizoaffective Disorder: A Randomized Double-Blind Controlled Clinical Trial. Iranian Rehabilitation Journal. 2019; 17(4):359-368. http://dx.doi. org/10.32598/irj.17.4.359

doi ${ }^{\circ}$ http://dx.doi.org/10.32598/irj.17.4.359

\section{(c) (1) (8)}

Article info:

Received: 06 Jun 2019

Accepted: 10 Oct 2019

Available Online: 01 Dec 2019

Keywords:

Schizophrenia, Schizoaffective disorder, Obesity, Metformin, Antipsychotics

\begin{abstract}
Objectives: The effect of metformin on weight changes and some metabolic parameters in patients with schizophrenia and schizoaffective disorder was investigated in this study.

Methods: As a randomized double-blind controlled clinical trial, this study was performed from 2018 to 2019. A total of 66 obese patients (BMI $\geq 27)$ with schizophrenia and schizoaffective disorder, hospitalized in the departments of Razi Psychiatric Hospital, entered the study; then, they were randomly divided into intervention and control groups after completing the informed consent form. The patients received metformin or placebo for 12 weeks. The dose of metformin was gradually increased and in case of a patient's tolerance, was prescribed up to $500 \mathrm{mg}$ twice daily. During the study, all patients received their previous therapies. The variables included BMI, weight, waist circumference, lipid profile, and fasting blood glucose, which were studied at the beginning of the study and at weeks 4,8 , and, 12 . The data were analyzed, using a post hoc test by SPSS software.
\end{abstract}

Results: The results showed a significant decrease in weight $(3.5 \mathrm{~kg})$ and BMI (1.30) at the end of the week 12 , and there was a significant reduction in waist circumference $(5.9 \mathrm{~cm})$ at the end of the week 8 compared to the placebo group $(\mathrm{P}<0.05)$. Moreover, metformin had no significant effect on fasting blood glucose and lipid profile in comparison with the placebo group.

Discussion: Based on the findings of this study, by reducing the weight, waist circumference, and BMI, metformin can have a significant role in decreasing the complications of obesity and metabolic disorders in patients with schizophrenia and schizoaffective disorder. Therefore, given that the complications of metformin are low and transient, it can be recommended as a safe and tolerable drug in obese patients with schizophrenia and schizoaffective disorder.

* Corresponding Author:

Gita Sadighi, PhD.

Address: Department of Psychiatry, University of Social Welfare and Rehabilitation Sciences, Tehran, Iran.

Tel: +98 (21) 33401604

E-mail: guitasadighi@gmail.com 


\section{Highlights}

- Obesity and overweight are distressing to psychiatric patients, which may have consequences for adherence to treatment, and affect the outcomes of rehabilitation programs.

- The administration of metformin $1000 \mathrm{mg} /$ day for 12 weeks for obese patients with schizophrenia and schizoaffective disorder can reduce the weight and BMI of patients in week 12 and decrease waist circumference in week 8 .

- Metformin had no significant effect on the reduction of serum fasting blood glucose and lipid profiles compared with the placebo group.

\section{Plain Language Summary}

Obesity and the risk of cardiovascular disease are high in patients with schizophrenia and significantly cause premature death in these patients, but the use of metformin prevents adverse outcomes.

\section{Introduction}

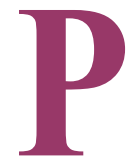

atients with schizophrenia and schizoaffective disorder are at the risk of metabolic complications of antipsychotics, including weight gain, hyperlipidemia, and glucose metabolic disorders. These drugs can increase the risk of heart disease and the risk of death from obesity in these patients. Cardiovascular diseases cause at least $50 \%$ of deaths in patients with schizophrenia. Studies have shown that the side effects of antipsychotics can increase the risk of heart disease and death in the next 10 years of patients' lives [1].

In psychiatric patients, obesity is associated with a severe decline in daily activities, sex life, work, energy, mobility, self-esteem, social/individual life, and physical function, leading to a decreased general quality of life and life satisfaction living. Moreover, obesity can affect the outcomes of rehabilitation programs in psychiatric patients [2].

The treatment of obesity is more challenging for patients receiving antipsychotic medications [3]. According to Centorrino et al., eating less food and exercising more is extremely difficult for mentally-ill patients because their treatment increases appetite, causing sedation and fatigue; on the other hand, their illnesses reduce motivation and cause limited social activities and interactions [3].

Despite the importance of this issue, few studies are available to control weight gain and metabolic problems caused by antipsychotics [4]. Among the Food and Drug Administration (FAD)-approved weight-reducing drugs, there are few drugs for patients with schizophrenia [5]. Sympathomimetic drugs such as phentermine, as well as a combination of topiramate and phentermine, are relatively contraindicated because of the possible risk of psychosis aggravation [6]. Orlistat, a pancreatic lipase inhibitor, did not show any significant weight loss in overweight patients with schizophrenia in a 16-week study [7]. The safety and efficacy of other weight-reducing drugs, such as lorcaserin (a drug affecting serotonin receptors), as well as a combination of naltrexone and bupropion, are currently under study and evaluation for patients with schizophrenia [6].

Among the weight-reducing non-FDA-approved drugs, several meta-analyses have shown the moderate efficacy of metformin, topiramate, fenfluramine, and reboxetine for the treatment of weight gain caused by antipsychotics $[5,7]$. Metformin, belonging to biguanides, is a blood glucose-reducing agent that is approved by the FDA for the treatment of type 2 diabetes. The blood glucose is influenced by metformin through inhibiting liver gluconeogenesis and increasing peripheral insulin sensitivity. Metformin has no effect on insulin production and, thus, does not usually lead to hypoglycemia in patients.

In pre-diabetes and type 2 diabetic patients, metformin has a relative effect on patients' weight changes [6]. Various mechanisms, such as changes in gastric emptying speed with effect on glucagon-like receptors and appetite changes, are reported for metformin [8,9]. Although the effect of metformin on weight loss is proven, various studies conducted on the effect of metformin on weight changes in patients with obesity caused by antipsychotic drugs show controversial results. 
Metformin is reported to be a suitable drug for weight decrease in some studies, while some studies advise further investigation and others have considered it ineffective [10-17]. Winsberg et al. studied the effect of metformin on 35 patients with schizophrenia. Their results showed that weight loss in the metformin group was significantly different for the 8-week follow-up period compared with the control group. In case of positive results, the use of metformin could be recommended as a supportive treatment in psychiatric patients treated with antipsychotics to minimize the positive changes in weight and avoid complications from obesity.

The main aim of the current study was to evaluate the effect of metformin on weight changes and some metabolic parameters in patients with schizophrenia and schizoaffective disorder.

\section{Methods}

As a randomized double-blinded controlled clinical trial, this study was conducted in the Razi Psychiatric Hospital from 2018 to 2019 . A total of 66 obese patients with schizophrenia and schizoaffective disorder were selected based on the Diagnostic and Statistical Manual of Mental Disorders, fifth edition criteria. The inclusion criteria included age between 18 and 65 years, $\mathrm{BMI} \geq 27$, duration of illness for more than 1 year, receiving 1 or 2 FDA-approved atypical antipsychotic drugs, and no change in the type and dose of medications used during the past 1 month. No significant difference was found between the two groups in receiving other drugs and the dose of antipsychotics. These patients received the same diet at the Razi Hospital, and their basic physical activity was the same based on the program of the department of psychiatry. The exclusion criteria were determined based on the study of Dmitri et al. [8].

This study was approved by the Ethics Committee of the hospital (IR.USWR.REC.1397.124). The identifier code of the Iranian Registry of Clinical Trials (IRCT) is IRCT20180502039508N1. After obtaining informed consent in accordance with the guidelines of the $\mathrm{Na}$ tional Health and Medical Research Council, the participants were randomly divided into placebo and metformin groups $(n=33)$. The sample size of the study was calculated based on the following formula:

In this study, the individuals were randomly allocated to the two groups, using web-based software (https:// www.Randomization.com), and a random sequence of numbers was generated.Also, the statistician who generated the random sequence, the investigator who exam- ined the participants in terms of the inclusion and exclusion criteria and enrolled them in the study, and the researcher who assigned the participants to the groups were separated and independent of each other.

The patients received metformin or placebo for 12 weeks. The dose of metformin was gradually increased and in case of a patient's tolerance, it was prescribed up to $500 \mathrm{mg}$ twice daily. During the study, all patients received their previous therapies. In the metformin group, capsules containing metformin $(500 \mathrm{mg})$ and in the control group, placebo capsules containing $500 \mathrm{mg}$ of inert substance (starch powder) were given. In the first week, a capsule was given daily in the evening and after 1 week, a capsule was added in the morning (up to a maximum dose of $1 \mathrm{~g}$ per day) if tolerated by patients. During this period, the patients were scheduled for a physician visit, and their vital signs and side effects were studied.

The patients would be excluded from the study if drug complications or intolerance to dose increasing happened. Weight loss and the improvement of some metabolic indices in patients with schizophrenia and schizoaffective disorder were the primary and secondary outcome measures, respectively. The variables, including BMI, weight, waist circumference, lipid profile, and fasting blood glucose were studied at the beginning of the study and at weeks 4,8 , and 12 for each patient. In order to maintain blindness, the study medication was prepared by a nurse not involved in patient care. The patients were not aware of the type of treatment received.

During the research period, no patient had any problem related to drug complications (based on the drug complications checklist) and was not excluded from the research; however, only one of the patients treated with metformin had gastrointestinal symptoms (nausea) in the first week, after which symptoms improved at the end of the first week. Mean and Standard Deviation (SD) were used for quantitative variables, and frequency tables were used for classification variables. The data were analyzed by SPSS V. 22, using an independent $t$ test. The significance level for all tests was considered to be $5 \%$.

\section{Results}

\section{Patients' Characteristics}

In the present study, patients with schizophrenia and schizoaffective disorder hospitalized in the departments of Razi Psychiatric Hospital were investigated. Totally, 66 individuals, who agreed to be present in the study, were randomly selected to receive metformin or place- 
bo. Of them, 33 received metformin and 33 received a placebo. Table 1 presents the demographic and clinical characteristics of the patients.

Comparison of the mean of variables at different times in the two groups

Table 2 presents the mean weight, BMI, waist circumference, fasting blood glucose, total cholesterol, LowDensity Lipoprotein (LDL), high-density lipoproteins (HDL), and triglyceride serum levels at different times of study.

Based on the results (Table 2), before starting the treatment and in the week 4 and week 8 of study, the mean weight and BMI (SD) in the metformin group did not significantly differ with the placebo group ( $\mathrm{P}>0.05)$; however, the mean weight and BMI in the week 12 of study showed a significant difference between the two groups $(\mathrm{P}<0.05)$. Before the treatment and in the week 4 , the mean waist circumference (SD) in the metformin group showed no significant difference with the placebo group ( $\mathrm{P}>0.05)$; however, significant differences were observed for the mean waist circumference in the weeks 8 and 12 between the two groups $(\mathrm{P}<0.05)$. No significant difference $(\mathrm{P}>0.05)$ was found for the mean serum level of fasting blood glucose and lipid profiles (total cholesterol, LDL cholesterol, HDL cholesterol, and triglyceride) between the metformin and placebo groups during the study (before treatment, week 4, week 8 , and week 12). Figure 1 shows the comparison of mean weight, BMI, and waist circumference at 4-time points.

Mean changes in the variables studied before the beginning of the study and in the week 12 and Table 3 presents the mean changes in the variables between weeks 0 and 12 in the metformin and placebo groups. The mean weight changes during 12 weeks of treatment was -3.50 $\mathrm{kg}$ (confidence interval $95 \%=2.66-4.34$ ) for the intervention group (metformin) and $4 \mathrm{~kg}$ (confidence interval

Table 1. Demographic and clinical characteristics of the study patients (overweight with schizophrenia or schizoaffective disorder) treated with metformin or placebo

\begin{tabular}{|c|c|c|c|c|}
\hline \multirow{2}{*}{\multicolumn{2}{|c|}{ Variable }} & \multicolumn{2}{|c|}{$\mathbf{N}(\%)$} & \multirow{2}{*}{$\mathbf{P}$} \\
\hline & & Metformin $(n=33)$ & Placebo $(n=33)$ & \\
\hline \multirow{2}{*}{$\stackrel{\times}{\sim}$} & Male & $24(72.7 \%)$ & $20(60.6 \%)$ & \multirow{2}{*}{0.340} \\
\hline & Female & $9(27.3 \%)$ & $13(39.4 \%)$ & \\
\hline \multirow{3}{*}{ 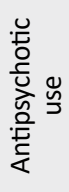 } & Higher-risk agents causing weight gain (Clozapine-Olanzaoine) & $11(33.3 \%)$ & $10(30.3 \%)$ & - \\
\hline & Lower-risk agents causing weight gain (Risperidone-Quetiapine) & $18(54.5 \%)$ & $20(60.6 \%)$ & - \\
\hline & Both higher- and lower-risk agents & $4(12.1 \%)$ & $3(9.0 \%)$ & - \\
\hline & Variable & Mean \pm SD & Mean \pm SD & $\mathbf{P}$ \\
\hline & Age (Years) & $47 \pm 8.50$ & $48.1 \pm 12.34$ & 0.782 \\
\hline & Weight (kg) & $87.03 \pm 12.54$ & $89.30 \pm 30.60$ & 0.848 \\
\hline & $\mathrm{BMI}\left(\mathrm{kg} / \mathrm{m}^{2}\right)$ & $31.66 \pm 3.79$ & $32.79 \pm 3.18$ & 0.325 \\
\hline & Waist Circumference (cm) & $112.97 \pm 8.52$ & $115.40 \pm 8.01$ & 0.442 \\
\hline & $\mathrm{FBS} \mathrm{mg} / \mathrm{dL}$ & $97.06 \pm 17.96$ & $95.50 \pm 11.75$ & 0.943 \\
\hline & Total Cholesterol mg/dL & $189.94 \pm 42.57$ & $184.40 \pm 37.01$ & 0.829 \\
\hline & $\mathrm{LDL}$ (mg/dL) & $109.39 \pm 29.34$ & $116.30 \pm 29.06$ & 0.516 \\
\hline & $\mathrm{HDL}(\mathrm{mg} / \mathrm{dL})$ & $41.72 \pm 9.59$ & $41.50 \pm 12.08$ & 0.885 \\
\hline & Triglyceride & $140.50 \pm 75.84$ & $109.20 \pm 40.95$ & 0.362 \\
\hline
\end{tabular}


Table 2. Comparison of the mean of variables studied at different times in the two groups

\begin{tabular}{|c|c|c|c|c|c|c|c|c|c|c|c|c|}
\hline \multirow{3}{*}{ Variables } & \multicolumn{12}{|c|}{ Mean \pm SD } \\
\hline & \multicolumn{3}{|c|}{ Week 0} & \multicolumn{3}{|c|}{ Week 4} & \multicolumn{3}{|c|}{ Week 8} & \multicolumn{3}{|c|}{ Week 12} \\
\hline & $\begin{array}{l}\text { Metfor- } \\
\text { min }\end{array}$ & $\begin{array}{l}\text { Pla- } \\
\text { cebo }\end{array}$ & $\mathbf{P}$ & $\begin{array}{c}\text { Metfor- } \\
\text { min }\end{array}$ & $\begin{array}{l}\text { Pla- } \\
\text { cebo }\end{array}$ & $\mathbf{P}$ & $\begin{array}{c}\text { Metfor- } \\
\text { min }\end{array}$ & $\begin{array}{l}\text { Pla- } \\
\text { cebo }\end{array}$ & $\mathbf{P}$ & $\begin{array}{l}\text { Metfor- } \\
\text { min }\end{array}$ & $\begin{array}{l}\text { Pla- } \\
\text { cebo }\end{array}$ & $\mathbf{P}$ \\
\hline Weight (kg) & $\begin{array}{c}87.03 \\
(12.54)\end{array}$ & $\begin{array}{c}89.30 \\
(30.60)\end{array}$ & 0.848 & $\begin{array}{c}85.33 \\
(13.28)\end{array}$ & $\begin{array}{c}90.00 \\
(13.27)\end{array}$ & 0.348 & $\begin{array}{c}84.56 \\
(13.01)\end{array}$ & $\begin{array}{c}91.20 \\
(13.41)\end{array}$ & 0.156 & $\begin{array}{c}83.53 \\
(12.97)\end{array}$ & $\begin{array}{c}93.00 \\
(71.13)\end{array}$ & 0.039 \\
\hline $\mathrm{BMI}\left(\mathrm{kg} / \mathrm{m}^{2}\right)$ & $\begin{array}{l}31.66 \\
(3.79)\end{array}$ & $\begin{array}{l}32.79 \\
(3.18)\end{array}$ & 0.325 & $\begin{array}{l}31.02 \\
(3.83)\end{array}$ & $\begin{array}{l}33.09 \\
(3.07)\end{array}$ & 0.150 & $\begin{array}{l}30.74 \\
(3.80)\end{array}$ & $\begin{array}{l}33.36 \\
(3.07)\end{array}$ & 0.076 & $\begin{array}{l}30.36 \\
(3.82)\end{array}$ & $\begin{array}{l}34.27 \\
(3.24)\end{array}$ & 0.010 \\
\hline $\begin{array}{l}\text { Waist cir- } \\
\text { cumference } \\
(\mathrm{cm})\end{array}$ & $\begin{array}{c}112.97 \\
(8.52)\end{array}$ & $\begin{array}{l}115.40 \\
(8.01)\end{array}$ & 0.442 & $\begin{array}{l}110.28 \\
(8.67)\end{array}$ & $\begin{array}{l}115.80 \\
(8.02)\end{array}$ & 0.093 & $\begin{array}{l}108.03 \\
(8.96)\end{array}$ & $\begin{array}{l}116.35 \\
(8.29)\end{array}$ & 0.035 & $\begin{array}{c}107.00 \\
(8.92)\end{array}$ & $\begin{array}{c}117.30 \\
(8.09)\end{array}$ & 0.007 \\
\hline $\begin{array}{c}\text { Fasting } \\
\text { blood } \\
\text { glucose }(\mathrm{mg} / \\
\mathrm{dL})\end{array}$ & $\begin{array}{c}97.06 \\
(17.96)\end{array}$ & $\begin{array}{c}95.50 \\
(11.75)\end{array}$ & 0.943 & $\begin{array}{c}95.84 \\
(17.79)\end{array}$ & $\begin{array}{c}94.70 \\
(12.11)\end{array}$ & 0.597 & $\begin{array}{c}94.39 \\
(16.54)\end{array}$ & $\begin{array}{c}94.20 \\
(11.83)\end{array}$ & 0.471 & $\begin{array}{c}96.56 \\
(19.33)\end{array}$ & $\begin{array}{c}94.30 \\
(11.50)\end{array}$ & 0.665 \\
\hline $\begin{array}{l}\text { Total choles- } \\
\text { terol }\end{array}$ & $\begin{array}{l}189.94 \\
(42.57)\end{array}$ & $\begin{array}{l}184.40 \\
(37.01)\end{array}$ & 0.829 & $\begin{array}{l}186.00 \\
(44.80)\end{array}$ & $\begin{array}{l}175.40 \\
(33.06)\end{array}$ & 0.388 & $\begin{array}{l}182.72 \\
(42.27)\end{array}$ & $\begin{array}{l}176.40 \\
(33.21)\end{array}$ & 0.773 & $\begin{array}{l}183.06 \\
(43.98)\end{array}$ & $\begin{array}{l}184.90 \\
(38.21)\end{array}$ & 0.719 \\
\hline LDL & $\begin{array}{l}10939 \\
(29.34)\end{array}$ & $\begin{array}{l}116.30 \\
(29.06)\end{array}$ & 0.516 & $\begin{array}{l}109.58 \\
(29.17)\end{array}$ & $\begin{array}{l}105.95 \\
(22.55)\end{array}$ & 0.718 & $\begin{array}{l}111.89 \\
(30.84)\end{array}$ & $\begin{array}{l}106.30 \\
(23.19)\end{array}$ & 0.647 & $\begin{array}{l}107.56 \\
(31.35)\end{array}$ & $\begin{array}{l}112.60 \\
(29.19)\end{array}$ & 0.427 \\
\hline $\mathrm{HDL}$ & $\begin{array}{l}41.72 \\
(9.59)\end{array}$ & $\begin{array}{c}41.50 \\
(12.08)\end{array}$ & 0.885 & $\begin{array}{l}43.31 \\
(8.17)\end{array}$ & $\begin{array}{l}43.95 \\
(8.39)\end{array}$ & 0.866 & $\begin{array}{l}42.61 \\
(8.13)\end{array}$ & $\begin{array}{l}42.80 \\
(8.79)\end{array}$ & 0.791 & $\begin{array}{l}43.61 \\
(7.92)\end{array}$ & $\begin{array}{l}43.90 \\
(8.84)\end{array}$ & 0.669 \\
\hline Triglyceride & $\begin{array}{l}140.50 \\
(75.84)\end{array}$ & $\begin{array}{l}109.20 \\
(40.95)\end{array}$ & 0.362 & $\begin{array}{l}151.78 \\
(80.30)\end{array}$ & $\begin{array}{l}117.80 \\
(42.46)\end{array}$ & 0.230 & $\begin{array}{l}149.89 \\
(73.32)\end{array}$ & $\begin{array}{l}121.70 \\
(42.78)\end{array}$ & 0.374 & $\begin{array}{l}150.44 \\
(79.07)\end{array}$ & $\begin{array}{l}119.70 \\
(43.46)\end{array}$ & 0.259 \\
\hline
\end{tabular}

Ilranian Rehabilitation „ourna

$95 \%=5.12-2.88)$ for the control group (placebo) with a between-group difference of $-7.5 \mathrm{~kg}(\mathrm{P}=0.000)$.

The mean BMI changes across 12 weeks of treatment was -1.30 (confidence interval 95\%=-0.98--1.61) for the metformin group and 1.48 (confidence interval $95 \%=1.92-1.04$ ) for the placebo group with a betweengroup difference of $-2.78(\mathrm{P}=0.007)$.

The mean waist circumference changes across 12 weeks of treatment was -5.97 (confidence interval 95\%=-5.12-6.82 ) for the metformin group and 1.90 (confidence interval $95 \%=2.40-1.40$ ) for the placebo group with a between-group difference of -7.87 $(\mathrm{P}=0.006)$.
The mean fasting blood sugar level changes across 12 weeks of treatment was -0.50 (confidence interval $95 \%=4.66-5.66$ ) for the metformin group and -1.20 (confidence interval $95 \%=4.18--6.58$ ) for the placebo group with a between-group difference of $0.7(\mathrm{P}=0.763)$.

The mean total cholesterol changes across 12 weeks of treatment was -1.89 (confidence interval $95 \%=3.21$ -6.99) for the metformin group and 0.50 (confidence interval $95 \%=23.20--22.20)$ for the placebo group with a between-group difference of $-2.39(\mathrm{P}=0.968)$.

The mean LDL cholesterol changes across 12 weeks of treatment was -1.83 (confidence interval $95 \%=3.21$ -
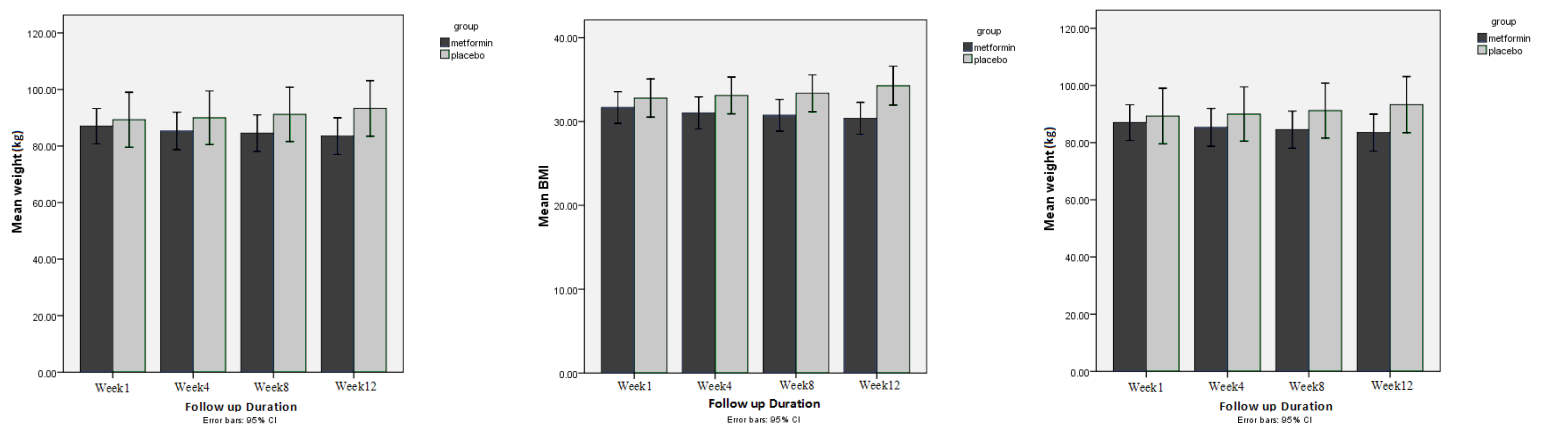

Figure 1. The comparison of mean weight, BMI, and waist circumference at 4-time points 
Table 3. The mean changes of variables between week 0 and week 12

\begin{tabular}{|c|c|c|c|c|c|c|c|c|}
\hline \multirow[t]{2}{*}{ Variable } & \multicolumn{2}{|c|}{ Metformin (n=33) } & \multicolumn{2}{|c|}{ Placebo $(n=33)$} & \multicolumn{2}{|c|}{$\begin{array}{l}\text { Between-group } \\
\text { Difference }\end{array}$} & \multicolumn{2}{|c|}{$\begin{array}{c}\text { Comparison of } \\
\text { Metformin with Placebo }\end{array}$} \\
\hline & Mean & $95 \% \mathrm{Cl}$ & Mean & $95 \% \mathrm{Cl}$ & Mean & $95 \% \mathrm{Cl}$ & $\mathbf{T}$ & $\mathbf{P}$ \\
\hline Weight (kg) & -3.50 & $\begin{array}{c}-2.66 \text { to } \\
-4.34\end{array}$ & 4.00 & $\begin{array}{l}5.12 \text { to } \\
2.88\end{array}$ & -7.5 & $\begin{array}{l}4.56 \text { to } \\
-16.60\end{array}$ & -1.369 & 0.000 \\
\hline $\mathrm{BMI}\left(\mathrm{kg} / \mathrm{m}^{2}\right)$ & -1.30 & $\begin{array}{c}-0.98 \text { to } \\
-1.61\end{array}$ & 1.48 & $\begin{array}{l}1.92 \text { to } \\
1.04\end{array}$ & -2.78 & $\begin{array}{l}0.397 \text { to } \\
-5.437\end{array}$ & -3.153 & 0.007 \\
\hline Waist circumference $(\mathrm{cm})$ & -5.97 & $\begin{array}{l}-5.12 \text { to } \\
-6.82\end{array}$ & 1.90 & $\begin{array}{c}2.40 \text { to } \\
1.40\end{array}$ & -7.78 & $\begin{array}{l}0.502 \text { to } \\
-13.230\end{array}$ & -3.630 & 0.006 \\
\hline $\begin{array}{l}\text { Fasting blood glucose } \\
\qquad(\mathrm{mg} / \mathrm{dL})\end{array}$ & -0.50 & $\begin{array}{l}4.66 \text { to } \\
-5.66\end{array}$ & -1.20 & $\begin{array}{l}4.18 \text { to } \\
-6.58\end{array}$ & 0.7 & $\begin{array}{l}14.775 \text { to } \\
-10.964\end{array}$ & 0.093 & 0.763 \\
\hline Total cholesterol & -1.89 & $\begin{array}{l}3.21 \text { to } \\
-6.99\end{array}$ & 0.50 & $\begin{array}{l}23.20 \text { to } \\
-22.20\end{array}$ & -2.39 & $\begin{array}{l}31.880 \text { to } \\
-33.180\end{array}$ & -0.002 & 0.968 \\
\hline LDL & -1.83 & $\begin{array}{l}3.16 \text { to } \\
-6.82\end{array}$ & -3.70 & $\begin{array}{l}15.36 \text { to } \\
-22.76\end{array}$ & 1.87 & $\begin{array}{l}17.215 \text { to } \\
-29.171\end{array}$ & 0.281 & 0.601 \\
\hline $\mathrm{HDL}$ & 1.89 & $\begin{array}{l}5.29 \text { to } \\
-1.51\end{array}$ & 2.40 & $\begin{array}{l}6.02 \text { to } \\
-1.22\end{array}$ & -0.51 & $\begin{array}{l}7.194 \text { to } \\
-7.260\end{array}$ & -0.014 & 0.993 \\
\hline Triglyceride & 9.94 & $\begin{array}{c}23.34 \text { to } \\
-3.45\end{array}$ & 10.50 & $\begin{array}{c}35.34 \text { to } \\
-14.34\end{array}$ & -0.56 & $\begin{array}{l}84.298 \text { to } \\
-22.254\end{array}$ & -1.433 & 0.242 \\
\hline
\end{tabular}

Iranian Rehabilitation Journal

-6.99) for the metformin group and -3.70 (confidence interval $95 \%=15.36--22.76)$ for the placebo group with a between-group difference of $1.87(\mathrm{P}=0.601)$.

The mean HDL cholesterol changes across 12 weeks of treatment was 1.89 (confidence interval 95\% = 5.29-1.51) for the metformin group and 2.40 (confidence interval $95 \%=6.02-1.22$ ) for the placebo group with a between-group difference of $-0.51(\mathrm{P}=0.993)$.

The mean triglyceride changes across 12 weeks of treatment was 9.94 (confidence interval 95\% = 23.34-3.45) for the metformin group and 10.50 (confidence interval $95 \%=35.34--14.34$ ) for the placebo group with a between-group difference of - $-0.56(\mathrm{P}=0.993)$.

\section{Discussion}

Obesity and overweight are distressing to psychiatric patients, which may have consequences for adherence to treatment by these individuals. Because of the negative quality of life outcomes of obesity, as well as health risks, preventing weight gain and effective weight management are of particular importance in the treatment of people having a psychiatric illness [18].

The aim of this study was to investigate the effect of metformin on weight loss and metabolic control in obese patients having schizophrenia and schizoaffective disorder. For this purpose, 66 patients, who suffered from schizophrenia and schizoaffective disorder according to the Diagnostic and Statistical Manual of Mental Disorders, fifth edition criteria, were studied in two groups receiving metformin and placebo for 12 weeks. The patients could use any of the atypical antipsychotics and stable doses of other drugs. Diabetes and conditions increasing the risk of metformin-induced lactic acidosis were the limitations of medication to enter the study. Therefore, the results of this study can be generalized and applicable to a wide range of patients. At the end of the $12^{\text {th }}$ week, the results showed a significant decrease in weight (3.5 kg), BMI (1.30), and waist circumference $(5.9 \mathrm{~cm})$ compared to the control group. This result is consistent with the findings of Wang et al., Jarskog et al., and Wu et al.; however, the weight loss rate was different in these studies. No significant weight loss was reported in the study conducted by Baptista et al.

The rate of weight loss may be affected by ethnicity. For instance, the most weight loss is reported in East Asian patients (Chinese). In two studies, a weight loss of $4.9 \%$ and $4.1 \%$ were reported in the metformin group for Chinese patients [11]. Also, the weight loss will be higher $(7.3 \%)$, when metformin is combined with diet and exercise regimens [12]. Treatment with metformin has had a lesser impact on Hispanic patients. In two studies, Hispanic patients showed a weight loss of 1.4 $\mathrm{kg}$ and $1.87 \mathrm{~kg}[15,16]$. The results of a study in the United States for patients with BMI $>27$ showed that after receiving metformin, the mean weight of patients decreased by $3 \mathrm{~kg}(2.8 \%)$ [6]. Based on the results of previous studies, a one-unit increase in BMI in patients 
receiving antipsychotic drugs is an important indication for initiating a therapeutic intervention to control weight gain in these patients [19].

In the present study, it was found that metformin reduced BMI by more than 1 unit within 12 weeks; however, given that achieving the desired weight loss in these patients requires continued treatment with metformin beyond 12 weeks, it is necessary to determine whether continued treatment with metformin beyond 12 weeks can cause decreased BMI or not. In this regard, the results of a study on 84 non-obese women with schizophrenia, who were in the first episode of amenorrhea and received metformin for 6 months, indicated a significant weight reduction in these patients compared to placebo [14]. Also, evidence of weight loss is reported in pre-diabetes and type 2 diabetic patients receiving metformin for 12 months [9, 20]. Weight loss methods in patients with schizophrenia are limited. In the United States, in addition to metformin, topiramate is the only marketed drug, and the results of a metaanalysis showed that this drug can lead to a significant weight loss (about $2.5 \mathrm{~kg}$ ) [5].

Another pharmacological approach to weight loss in this population is to change the type of antipsychotic drug with less weight gain. Studies show significant weight loss, using this method $[21,22]$.

Although in these studies changing the type of antipsychotics is generally safe and does not lead to relapses, the change of antipsychotics should be done with considerable clinical care and supervision. Overall, based on the results of studies, where metformin is prescribed with antipsychotics, metformin is one of the few safe and effective methods for overweight patients, who use antipsychotics. The focus of previous studies was on the effect of metformin on antipsychotics weight gain in the first attack of schizophrenia. For example, the results of a study on 128 Chinese adults with schizophrenia, whose baseline weight increased by $10 \%$ because of receiving antipsychotics, showed that metformin with a behavioral intervention can result in an average weight loss of $4.7 \mathrm{~kg}$ after 12 weeks of treatment, while behavioral intervention alone resulted in an average loss of $1.4 \mathrm{~kg}$ in weight [12].

A comparison of these findings with the data of the current study reveals the higher efficiency of metformin to reduce weight in patients with the first attack of psychosis. In adults with chronic psychosis, two studies showed no significant changes in the weight loss between metformin and placebo. In the first study, there were 40 hospitalized patients (mean BMI of 23), who started receiving Olanzapine [16]; however, in the second study, 80 patients were already receiving Olanzapine [23]. In a study, in which 61 chronic patients received clozapine (mean BMI of 28), a small difference was observed between placebo and metformin after 14 weeks [15]. In the previous studies, the effects of metformin on lipid profiles in schizophrenic patients are not measured [11].

The results of the present study showed that metformin had no significant effect on serum triglyceride, HDL cholesterol, and LDL cholesterol. Also, in a study on patients receiving clozapine, no different effect of metformin on serum lipids was reported, which is consistent with our results [15]. Although, in the study performed by Jarskog et al. not all patients, who were included in the study, had abnormal serum lipid levels and the average serum lipid level was abnormal or nearer to it [24]. The results of this study showed that metformin caused a significant reduction in serum triglyceride levels $(-2 \mathrm{mg} /$ $\mathrm{mL})$, which did not match our results [6]

The reason for this discrepancy is the difference in average serum lipid levels in patients entering the study. The fasting glucose levels showed no changes between metformin and placebo groups during the study. This can be because of the short duration of the study so that more duration is likely needed to reveal the effects of metformin on reducing blood glucose levels in people with normal blood glucose levels. This finding is consistent with the results of a study by Man Wang et al., in which the level of fasting insulin in the two groups was significantly different, but the fasting blood glucose level did not change [10].

In contrast, the result of this study is inconsistent with the findings of Wang et al. in patients with schizophrenia, in which metformin was associated with a decrease in fasting glucose compared with placebo. This discrepancy can be as a result of differences in diet, pathophysiology, and pharmacokinetics between the two studied populations. In general, although in this study the mean serum glucose level did not show significant differences between the two groups, metformin has benefits in preventing diabetes in pre-diabetes patients; it indicates the fact that diabetes prevention can be another potential benefit of metformin for obese patients with schizophrenia and schizoaffective disorder in long term [21].

The length of the study period (12 weeks) was one of the limitations of this study. Therefore, it should be determined whether losing weight will be sustained in these patients by stopping treatment with metformin. The sec- 
ond limitation, not addressed in this study, was whether nutritional or behavioral interventions along with metformin therapy could be more effective in controlling the weight of patients. The results of a study, in which the patients receiving antipsychotics had more than $10 \%$ weight gain, showed that metformin along with lifestyle modification had an additive effect on weight loss [12].

\section{Conclusion}

Based on the results of this study, the administration of metformin $1000 \mathrm{mg}$ /day for 12 weeks for obese patients with schizophrenia and schizoaffective disorder can reduce the weight and BMI of patients in week 12 and decrease waist circumference in week 8. Moreover, metformin had no significant effect on the reduction of serum fasting blood glucose and lipid profiles compared with the placebo group. The results of this study clearly showed that because of the low and transient side effects of metformin, this drug can be regarded as safe and tolerable for weight reduction in obese patients with schizophrenia and schizoaffective disorder.

\section{Ethical Considerations}

\section{Compliance with ethical guidelines}

This study was approved by the hospital ethics committee (IR.USWR.REC.1397.124). The identifier code of Iranian Registry of Clinical Trials (IRCT) is IRCT20180502039508N1

\section{Funding}

The authors received no financial support for the research, authorship, and or publication of this article.

\section{Authors' contributions}

Conceptualization, formal analysis: Maryam Aghaye Rashti, Gita Sadighi; Methodology, Software: Mohammad Reza Khodaei, Bahman Dieji, Mehdi Nowrouzi; Investigation, writing-original draft; Mahboubeh Sabaghi; Writingreview and editing: Sasan Zandi Esfahan.

\section{Conflict of interest}

The authors declare no conflict of interest.

\section{Acknowledgments}

The authors acknowledge their gratitude to Dr. Ehsan Zandi Esfahan, a member of scientific board, Research Institute of
Forests and Rangelands, for academic writing and editing the manuscript.

\section{References}

[1] Daumit GL, Goff DC, Meyer JM, Davis VG, Nasrallah HA McEvoy JP, et al. Antipsychotic effects on estimated 10year coronary heart disease risk in the CATIE schizophrenia study. Schizophrenia Research. 2008; 105(1-3):175-87. [DOI:10.1016/j.schres.2008.07.006] [PMID] [PMCID]

[2] Kolotkin RL, Head S, Hamilton M, Tse CKJ. Assessing impact of weight on quality of life. Obesity Research. 1995, 3(1):49-56. [DOI:10.1002/j.1550-8528.1995.tb00120.x] [PMID]

[3] Centorrino F, Wurtman J, Duca K, Fellman V, Fogarty K, Berry J, et al. Weight loss in overweight patients maintained on atypical antipsychotic agents. International Journal of Obesity. 2006; 30(6):1011-16. [DOI:10.1038/sj.ijo.0803222] [PMID]

[4] Henderson DC, Nguyen DD, Copeland PM, Hayden DL, Borba CP, Louie PM, et al. Clozapine, diabetes mellitus, hyperlipidemia, and cardiovascular risks and mortality: Results of a 10-year naturalistic study. Journal of Clinical Psychiatry 2005; 66(9):1116-21. [DOI:10.4088/JCP.v66n0905] [PMID]

[5] Maayan L, Vakhrusheva J, Correll CU. Effectiveness of medications used to attenuate antipsychotic-related weight gain and metabolic abnormalities: A systematic review and meta-analysis. Neuropsychopharmacology. 2010; 35(7):1520 [DOI:10.1038/npp.2010.21] [PMID] [PMCID]

[6] Jarskog LF, Hamer RM, Catellier DJ, Stewart DD, LaVange L, Ray N, et al. Metformin for weight loss and metabolic control in overweight outpatients with schizophrenia and schizoaffective disorder. American Journal of Psychiatry. 2013 170(9):1032-40. [DOI:10.1176/appi.ajp.2013.12010127] [PMID] [PMCID]

[7] Björkhem-Bergman L, Asplund AB, Lindh JD. Metformin for weight reduction in non-diabetic patients on antipsychotic drugs: A systematic review and meta-analysis. Journal of Psychopharmacology. 2011; 25(3):299-305. [DOI:10.1177/0269881109353461] [PMID]

[8] Dmitri K, McFarlane Samy I, Sowers James R. Metformin: An update. Annals of Internal Medicine. 2002; 137(1):25-33. [DOI:10.7326/0003-4819-137-1-200207020-00009] [PMID]

[9] DeFronzo RA, Goodman AM, Group MMS. Efficacy of metformin in patients with non-insulin-dependent diabetes mellitus. New England Journal of Medicine. 1995; 333(9):541-9. [DOI:10.1056/NEJM199508313330902] [PMID]

[10] Wang M, Tong J-h, Zhu G, Liang G-m, Yan H-f, Wang X-z. Metformin for treatment of antipsychotic-induced weight gain: A randomized, placebo-controlled study. Schizophrenia Research. 2012; 138(1):54-7. [DOI:10.1016/j. schres.2012.02.021] [PMID]

[11] Wu RR, Zhao JP, Guo XF, He YQ, Fang MS, Guo WB, et al. Metformin addition attenuates olanzapine-induced weight gain in drug-naive first-episode schizophrenia patients: a double-blind, placebo-controlled study. American Journal of Psychiatry. 2008; 165(3):352-8. [DOI:10.1176/appi. ajp.2007.07010079] [PMID] 
[12] Wu RR, Zhao JP, Jin H, Shao P, Fang MS, Guo XF, et al. Lifestyle intervention and metformin for treatment of antipsychotic-induced weight gain: A randomized controlled trial. JAMA. 2008; 299(2):185-93. [DOI:10.1001/jama.2007.56-b]

[13] Klein DJ, Cottingham EM, Sorter M, Barton BA, Morrison JA. A randomized, double-blind, placebo-controlled trial of metformin treatment of weight gain associated with initiation of atypical antipsychotic therapy in children and adolescents. American Journal of Psychiatry. 2006; 163(12):2072-9. [DOI:10.1176/ajp.2006.163.12.2072] [PMID]

[14] Wu RR, Jin H, Gao K, Twamley EW, Ou JJ, Shao P, et al. Metformin for treatment of antipsychotic-induced amenorrhea and weight gain in women with first-episode schizophrenia: a double-blind, randomized, placebo-controlled study. American Journal of Psychiatry. 2012; 169(8):813-21. [DOI:10.1176/appi.ajp.2012.11091432] [PMID]

[15] Carrizo E, Fernández V, Connell L, Sandia I, Prieto D, Mogollón J, et al. Extended release metformin for metabolic control assistance during prolonged clozapine administration: A 14 week, double-blind, parallel group, placebo-controlled study. Schizophrenia Research. 2009; 113(1):19-26. [DOI:10.1016/j. schres.2009.05.007] [PMID]

[16] Baptista T, Rangel N, Fernández V, Carrizo E, El Fakih Y, Uzcátegui E, et al. Metformin as an adjunctive treatment to control body weight and metabolic dysfunction during olanzapine administration: a multicentric, double-blind, placebocontrolled trial. Schizophrenia Research. 2007; 93(1-3):99-108. [DOI:10.1016/j.schres.2007.03.029] [PMID]

[17] Baptista T, Martínez J, Lacruz A, Rangel N, Beaulieu S, Serrano $\mathrm{A}$, et al. Metformin for prevention of weight gain and insulin resistance with olanzapine: A double-blind placebocontrolled trial. The Canadian Journal of Psychiatry. 2006; 51(3):192-6. [DOI:10.1177/070674370605100310] [PMID]

[18] Kolotkin RL, Corey-Lisle PK, Crosby RD, Swanson JM, Tuomari AV, L'Italien GJ, et al. Impact of obesity on healthrelated quality of life in schizophrenia and bipolar disorder. Obesity. 2008; 16(4):749-54. [DOI:10.1038/oby.2007.133] [PMID]

[19] Rummel-Kluge C, Komossa K, Schwarz S, Hunger H, Schmid F, Lobos CA, et al. Head-to-head comparisons of metabolic side effects of second generation antipsychotics in the treatment of schizophrenia: A systematic review and meta-analysis. Schizophrenia Research. 2010; 123(2-3):225-33. [DOI:10.1016/j.schres.2010.07.012] [PMID] [PMCID]

[20] Knowler WC, Barrett-Connor E, Fowler SE, Hamman RF, Lachin JM, Walker EA, et al. Reduction in the incidence of type 2 diabetes with lifestyle intervention or metformin. The New England Journal of Medicine. 2002; 346(6):393-403. [DOI:10.1056/NEJMoa012512] [PMID] [PMCID]

[21] Stroup TS, McEvoy JP, Ring KD, Hamer RH, LaVange LM, Swartz MS, et al. A randomized trial examining the effectiveness of switching from olanzapine, quetiapine, or risperidone to aripiprazole to reduce metabolic risk: Comparison of Antipsychotics for Metabolic Problems (CAMP). American Journal of Psychiatry. 2011; 168(9):947-56. [DOI:10.1176/appi. ajp.2011.10111609] [PMID] [PMCID]

[22] Newcomer JW, Campos JA, Marcus RN, Breder C, Berman RM, Kerselaers W, et al. A multicenter, randomized, doubleblind study of the effects of aripiprazole in overweight subjects with schizophrenia or schizoaffective disorder switched from olanzapine. The Journal of Clinical Psychiatry. 2008; 69(7):1046-56. [DOI:10.4088/JCP.v69n0702] [PMID]

[23] Winsberg B, Wei R, Elangovan N, Camp-Lifshitz J. Outpatient Metformin Management of Obese Individuals With Schizophrenia. The primary care companion for CNS disorders. 2014; 16(6):1-6. [DOI:10.4088/PCC.14101687] [PMID] [PMCID]

[24] Grundy SM, Cleeman JI, Merz CNB, Brewer HB, Clark LT, Hunninghake DB, et al. Implications of recent clinical trials for the national cholesterol education program adult treatment panel III guidelines. Journal of the American College of Cardiology. 2004; 44(3):720-32. [DOI:10.1016/j.jacc.2004.07.001] [PMID] 
This Page Intentionally Left Blank 